\title{
DESCRIPCIÓ I PRESCRIPCIÓ EN LA GRAMÀTICA DEL CATALÀ CONTEMPORANI (2002)
}

\author{
Joan Solà
}

Universitat de Barcelona

\section{GRAMÀTICA DESCRIPTIVA VS. PRESCRIPTIVA}

\subsection{Les nocions de variació, prescripció $i$ descripció}

El tema del simposi que avui ens reuneix preocupa darrerament diverses comunitats lingüístiques. També als territoris de llengua catalana es fan sovint col-loquis o conferències sobre aquesta qüestió, i fins hi ha grups de treball universitaris que duen noms com variació.

És possible que alguna de les persones implicades en aquests grups o en aquests colloquis no tingui clara la diferència entre $v a$ riació, descripció i prescripció, i potser per això abunden tant aquests actes: una manera d'arribar a saber què és la matèria en la qual treballes és preguntar-t'ho a tu mateix de manera constant, però també preguntar-ho als altres collegues. Com que a mi se m'ha invitat aquí a propòsit de la publicació de la Gramàtica del català contemporani $(G c c)$, els explicaré una anècdota molt significativa que ara ja no em fa vergonya però que abans sí que me'n feia. En una de les primeres reunions de la direcció de la Gcc vaig dir que algun colllaborador havia insinuat que no tenia clar què volia dir gramàtica descriptiva, que és el que pretenia ser la Gcc. Un membre de la direcció, Joan Mascaró, va dir, sense vacillar: "Doncs jo ho tinc ben clar". Jo vaig callar, perquè jo tampoc no ho tenia clar, gens clar, i em feia una cosa de confessar-ho davant els altres col-legues als quals precisament jo havia cridat a dirigir equell magne projecte: se suposava que si algú ho havia de tenir clar era jo. Ja veuen la paradoxa. Quan vam acabar l'obra, aleshores sí que ho vaig veure amb tota evidència, i ara estic satisfet d'haver après, entre una multitud d'altres coses (lingüístiques i no lingüístiques), aquesta, que és tan essencial per a qui es dedica a la llengua. 
¿Per què jo no tenia clara la diferència entre descripció i presripció i sí que la tenia clara Joan Mascaró? Ara ho puc expressar molt breument: doncs perquè jo m'havia dedicat tota la vida a la prescripció, a furgar en els detalls de les "gramàtiques" del nostre mercat, que eren totes prescriptives (que és sinònim de normatives, una sinonímia de la qual és possible que no tothom s'adoni immediatament). A mi, que tenia una intuïció relativament bona sobre els fets concrets de la meva llengua, m'interessava discutir i completar aquells manuals. Malgrat que m'havia preocupat d'eixamplar el meu horitzó, estudiant a fons el generativisme i fins i tot anant al Regne Unit a fer un màster en lingüística general, se'm feía dificil de percebre que hi havia dues rnaneres de veure aquells fets concrets de llengua. Un cop acabada la $G c c$, vaig veure que l'obra contenia una multitud de fets i de pàgines i fins i tot molts capítols que no afectaven per a res, o molt poc, aquells fets que a mi m'havien preocupat tota la vida. En canvi, Joan Mascaró havia tirat sempre per la via més aviat descriptiva i teòrica de la llengua: s'havia dedicat més buscar les lleis profundes dels fets visibles.

Doncs ara entenc aquelles nocions de la manera que diré tot seguit. Una gramàtica descriptiva intenta fer una radiografia del funcionament d'una llengua en la realitat quotidiana, cosa que equival a trobar i formular les lleis profundes dels fets visibles.

Igual que una radiografia mèdica, la verbalització d'aquest funcionament exigeix un metallenguatge concret i unívoc: què és un article, què vol dir verb d'acció, què vol dir oposició entre dues opcions, què són el gènere gramatical, l'aspecte verbal, la concordança negativa, què és el nucli d'una oració, què és una dislocació, què vol dir pragmàtica, semàntica, sintaxi, funció, seqüència, què és un complement i què és un adjunt, què és exactament un pronom i concretament què vol dir pronom personal. Etcètera. Nocions i paraules que has trobat milers de vegades en les teves lectures, però que no les "entens" profundament (pràcticament) fins que no et poses a treballar personalment en un projecte com aquest, sobretot si tu n'ets el director principal. Una descripció dóna compte de tots els fets que la ciència del moment considera rellevants: per exemple, analitza detingudament el sintagma nominal, tots i cada un dels seus components, i diu quines restriccions semàntiques i d'ordre respectiu manifesten els uns amb els altres. La majoria d'aquests fets no tenen cap "interès" per a una gramàtica normativa: cap catalanoparlant no "veu" res d'especial, d'interessant, en una seqüència com les tres primeres setmanes de juliol. 
Una gramàtica normativa (o preceptiva), sobretot aplicada a llengües com el gallec i el català, políticament perseguides durant segles i socialment barrejades amb la llengua del poder, es preocupa bàsicament o exclusivament d'aquells fets que contribueixen a distingir un escrit "correcte" d'un escrit "incorrecte", i per tant que ajuden de manera immediata els usuaris de bona voluntat que volen integrar en la seva vida aquella llengua bandejada, perseguida, ignorada. Però resulta que aquests dos qualificatius, correcte i incorrecte, són tan difícils de definir que aviat observem la dispersió a què un manual normatiu es veu abocat. I, efectivament, en la nostra gramàtica "escolar" (accepteu el sarcasme per a una llengua prohibida a l'escola) teníem a la banda de l'"incorrecte" tant un infinitiu com capiguer com un altre de la forma incurrir i una tercera persona singular de l'imperfet d'indicatiu en la forma anae (estàndard anava), etc. (1).

(1)
a [Infinitiu del verb cabre]
cabre, ?caber, ${ }^{+}$capiguer
b [Infinitiu del verb incórrer] incórrer, ${ }^{+}$incurrir
c [3a sg imperf ind] anava, portava, tenia... $\|^{+}$anae, ${ }^{+}$portae, ${ }^{+}$tenie, ${ }^{+}$teniva [occidental]

Ara bé: la forma incurrir (1b) és simplement una infiltració del castellà incurrir (verb de la tercera conjugació) en una forma tradicional segura incórrer (verb de la segona conjugació); en canvi, les altres formes que dono a (1) són simplement formes orals "normals" de diferents parlars ("normals", en el sentit de Coseriu: la norma de la societat o minisocietat que les usa correntment). Per tant, una gramàtica normativa no es fixará pas en la seqüència esmentada, les tres primeres setmanes de juliol, perquè no hi ha o no hi veu res a "corregir"; perquè a ningú no se li ocorrerà mai de dir o escriure "tres primeres les setmanes de juliol". És cert que algú es pregunta si també podem dir "les primeres tres setmanes de juliol", però això ja seria propi de gent molt "escrupolosa". En termes actuals: aquesta pregunta és simplement pròpia d'un gramàtic descriptiu, que analitza totes les possibilitats estructurals de les seqüències $i$, en el cas del sintagma nominal, especifica quina posició hi ocupen els articles, els quantificadors, els complements (2). 
(2)

a les tres primeres setmanes de juliol

b ?les primeres tres setmanes de juliol

c *tres primeres les setmanes de juliol

Finalment, la variació, aquest terme que avui s'ha posat de moda, segurament no vol dir gran cosa més que el tradicional de dialectologia, encara que potser té una mica més d'amplitud semàntica. En el nostre cas, afectaria formes com les de (1a, c). Com que un investigador necessita més terreny per moure's, sota el concepte de variació es podrien estudiar molts fenòmens sincrònics i diacrònics de la llengua, inclosos potser aspectes més aviat sociolingüistics (nivells de llenguatge, argots de grups socials, etc.). Tot, naturalment, ben emmarcat en les metodologies del moment.

\subsection{Altres exemples}

Els dono tot seguit uns altres exemples que faran veure la diferència entre descripció i prescripció, almenys si prenem com a objecte d'observació un manual qualsevol del mercat pedagògic i el comparem amb la Gcc.

En fonètica i fonologia, a una gramàtica normativa li interessa gairebé exclusivament aclarir si són o no són estàndards certes pronunciacions generals de la llengua o particulars de diferents dialectes. A (3a) dono tres casos d'aquests, i a la resta de (3) dono altres fenòmens que es troben a la Gcc:

(3) Fonètica i fonologia

a gràcia grà[sj]a $\|$ elefant [a]lefant $\|$ psiquiatre [s]iquiatre

b ¿Que veureu la Maria?\ II ¿Veureu la Maria?/

c Veureu la Maria II ¿Veureu la Maria? II Veureu LA MARIA

La nostra gramàtica normativa arrossega des de fa molts anys l'escrúpol de decidir si paraules com gràcia són bisíl·labes i trisíllabes. En català antic hi ha constància que eren trisíllabes o que almenys podien ser-ho. Però avui, i des de fa segles, són bisíl·labes, i així ho fa constar la Gcc. La primera vocal de la paraula elefant es pronuncia com si fos una $a$ en una part important dels parlars catalans (els occidentals), i la gramàtica normativa dictamina si tal pronunciació és acceptable en un noticiari de televisió o només ho fóra en una pel·lícula. La Gcc es preocupa de definir bé el fenomen i de delimitar-ne 
bé l'extensió: la resta no l'afecta. Així mateix, un locutor de ràdio vol saber si ha de pronunciar o no la $p$ de psiquiatre. La Gcc descriu llargament el fenomen de paraules cultes que tenen síl·labes d'aquesta mena, en dóna molts més exemples que el manual normatiu, i fa veure quines lleis profundes i tradicionals regeixen en català pel que fa a les possibilitats estructurals de les síllabes: amb la qual cosa ajuda també l'autoritat normativa a reconsiderar, si cal, la seva posició pel que fa a l'acceptabilitat d'una o altra pronunciació. Recordin que en castellà aquest afer desembocà en la simplificació fins i tot gràfica de tals síl·labes.

Però una gramàtica descriptiva (la Gcc) es preocupa de fets tan essencials per a una llengua com la prosòdia, aspecte que no havia interessat mai a la normativa. A (3b) veiem dues maneres de pronunciar una oració interrogativa: amb final ascendent (/) o amb final descendent $(\backslash)$. I a (3c) ens adonem que la prosòdia és sovint l'única manera que té una llengua de distingir dràsticament seqüències lèxicament i sintàcticament idèntiques (: la primera pronunciació és una afirmació, la segona és una pregunta i la tercera focalitza la Maria (fa contrastar aquest element respecte d'un altre del context). Observin en quins mons nous ens situa una gramàtica descriptiva i quin al-licient pot tenir fins i tot per als professors de llengua, que ja no cal que es limitin a torturar els alumnes amb correccions i incorreccions.

En morfologia, a (4a) tenen algun exemple dels interessos d'una normativa, i a la resta de (4) tenen altres fets que potser no formen o no han format part dels manuals normatius:

(4) Morfologia

a "Errors" en gènere i nombre: una / "un anàlisi II "Errors" en conjugació: escollir $\rightarrow$ escull / ${ }^{+}$escolleix; escriure $\rightarrow$ escrivís / escrigués

b cama 'perna' $\rightarrow$ c[ə]meta [Derivat] \| camatrencar [Compost]

c Joaquim $\rightarrow$ Quim/Ximo [Hipocorístic]; cine, ràdio, Montserrat $\rightarrow$ Rat/Montse [Truncament]; bup-bup [Onomatopeia]; DOGC [Sigla]; futbol, bulto [Manlleus]

En català hi ha paraules de gènere diferent de les corresponents castellanes (anàlisi és femenina, com en italià i en francès). I verbs com escollir i escriure presenten per a certs temps i persones formes 
diverses, entre les quals la normativa fa una selecció. La Gcc informa àmpliament de tals variacions dialectals, tant en els verbs "regulars" com en els "irregulars" (alhora que intenta redefinir aquests conceptes, que no són pas tan clars com la gent es creu i com els manuals escolars diuen).

Però la Gcc aborda moltes altres qüestions que ja cauen fora o més lluny de les necessitats prescriptives. En català oriental (el dialecte més important demogràficarnent i econòmicament) les vocals $a$ i $e$ es redueixen a vocals neutres quan són àtones. Així, és neutra l'última vocal de cama, i la primera $a$ també esdevé neutra en un derivat (diminutiu) com cameta. En canvi, els mots compostos no redueixen la vocal, encara que hagi esdevingut àtona, com en camatrencar (4b). A (4c) hi ha exemples d'un capítol de la Gcc que estudia els fenòmens exemplificats, que mai no havien sigut estudiats sistemàticament: els manuals de normativa es limitaven a indicar que tradicionalment els truncaments en noms propis es feien reduint $l^{\prime} i$ nici de la paraula (Montserrat $\rightarrow$ Rat) i no pas el final (Montserrat $\rightarrow$ Montse) i que aquesta segona reducció era un castellanisme. La Gcc deixa constància d'aquest canvi de sistema i l'estudia més sistemàticament. El concepte d'estudi sistemàtic és, doncs, essencial en una gramàtica descriptiva: només així s'arriben a conèixer fets fins ara ocults o mal coneguts (com el de camatrencar).

En sintaxi, la nostra normativa es preocupava de corregir fets interns de la llengua, com ara el desplaçament (en una part important del domini lingüístic, però no en valencià) de la combinació pronominal li’n per la combinació n'hi (5a) (avui el fenomen s'accepta en la pràctica); o de prohibirr solecismes com tenir que en lloc d'haver de per a les expressions d'obligació (5a).

La Gcc, a part d'estudiar aquests fenòmens i de dir com es troben avui normativament i socialment, estudia més sistemàticament les perífrasis verbals i explora molts altres aspectes tan essencials com els que indico a (5b), tradicionalment abandonats. Observin, per exemple, un cas ben simple d'el·lipsi: el català no té la construcció que dono a (5b), que és normal en castellà.

(5) Sintaxi

a Li donaré pa $\rightarrow$ Li'n / N’bi donaré $\|{ }^{+}$Tinc que venir $\rightarrow H e$ de venir

b Ordre de mots || Quantificadors || Condicions de pronominalització || El·lipsis [Me dijo lo que Ø tú Em va dir el mateix que tu] 
2. ACTitud DE LA GCC DAVANT LA NORMA LiNGÜístiCA

\subsection{L'estat actual de la llengua. Una certa crisi de la norma}

Com és inevitable en llengües perseguides i excloses durant tants segles de l'escola i dels àmbits de recerca, el català presenta avui molts punts que un dia es van "resoldre" d'una certa manera per qüestions d'urgència i que avui (a mesura que hi ha hagut investigació i presència pública de la llengua) es troben discutits o en situación vacil·lant. En dono una mostra a (6):

(6)

a Signes inicials $\dot{i}, ;$

¿Has vist la Maria? II ¿Quina calor!

b Per/per $a+$ INF

[Sistema "normatiu"] Parlo per distreure'l I| Això serveix per a netejar la pantalla

[Sistema Coromines-Solà: per + INF] Parlo per..., Això serveix per...

c Concordança del verb haver-hi

Hi ha / Hi han moltes dificultats

d Té bastant/ bastanta paciència

e Infinitiu temporal, amb en o amb al En /Al veure'l em vaig alegrar

f Duplicació pronominal

On (hi) diu tal cosa (hi) ha de dir tal altra

$\mathrm{g}$ Preposicions locatives $a$ i en

Veurem això \{al / en el\} capítol segon \| La formulació bàsica del fenomen és la de (2), exemplificada a/en (3)

$\mathrm{h}$ Pronominalització d'atributs definits

Sembla la meva mare però no bo és [?"l'és]

¿Dis que non é túa nai? Ser no a $\underline{\text { o }}$ será, pero parecer parécea $/ \underline{\mathrm{o}}$

i Concordança negativa o negació doble

Tampoc (no) la veuré jo

j Escriptura de paraules derivades i compostes

exgovernamental, sintacticosemàntic

Gcc: ex-governamental, sintàctico-semàntic 
Detalls com aquests i d'altres divideixen amb més o menys vehemència els usuaris (o, millor, els professionals) de la llengua en dos grups: els que treballen per a l'administració o que estan lligats a organismes oficials o que decideixen arrecerar-se en el que creuen que és la norma o el que creuen que ha dit l'autoritat, i els altres. No sé quin percentatge d'usuaris hi ha a cada banda, però podria ser que estigués equilibrat. De qualsevol manera, aquests detalls (i molts altres) es troben vacil-lants en tots dos grups, però especialment al primer. El problema és que avui la llengua catalana es troba en una situació social (i política) molt delicada, i això fa que molts usuaris es facin bandera d'aquesta mena de detalls i es creguin obligats a "respectar" la norma, com una manera de protegir la llengua, quan jo crec que la majoria d'aquests detalls no tenen cap mena d'influència en la salut pública de la llengua.

Paradoxalment, entre les qüestions que arriben a esdevenir emblemàtiques hi ha les més irrellevants per a l'estructura i la vitalitat de la llengua, com ara les ortogràfiques: l'ús dels signes inicials d'interrogació i exclamació (6a) ha arribat a enfrontar unes persones o institucions amb altres. De fet, el català té en aquest punt una estructura idèntica a la del castellà, i per tant li és imprescindible el signe inicial d'interrogació; el d'exclamació no és pragmàticament tan imprescindible. Però Fabra va creure que era millor que el català restringís l'ús d'aquests signes (i que així la llengua s'assemblés més a les altres llengües que només usen els signes finals).

Aquest estat de la llengua ha produit un fenomen ben explicable: la majoria dels manuals pràctics de gramàtica (i els diccionaris) prefereixen mantenir-se en una posició "ortodoxa". I davant els detalls controvertits o no aclarits pels codis oficials (gramàtica i diccionari), se situen implícitament o explícitament allà on creuen que es troba la norma o l'autoritat. Molt sovint l'autoritat o la norma no diuen res sobre un determinat detall, i per tant aquesta posició representa l'acceptació de pressupòsits "clàssics". Més d'un d'aquests pressupòsits avui es considera erroni o almenys revisable.

Donem-ne algun exemple. La nostra gramàtica "clàssica" tenia com a principi ben establert que les duplicacions pronominals (dites "pleonasmes") eren "faltes" de gramàtica i per tant s'havien d'evitar. Un exemple d'aquest fenomen seria En el segon capitol hi hem llegit les declaracions dels ministres, on es considerava que en el segon capítol i el pronom hi representaven el mateix constituent de l'oració i per tant hi havia un "pleonasme" que calia corregir així: En el segon capitol $\varnothing$ hem llegit les declaracions dels ministres. Però avui tothom 
dóna per bo que no hi ha duplicació sinó que en el segon capitol pot ser un adjunt locatiu dislocat, i en aquest cas hi hauria d'haver el pronom que el representa a l'interior de l'oració. Un altre cas és el de (6f): els investigadors han deixat clar, des de fa anys, que aquí el pronom fa la funció d'impersonalitzar el verb dir, no pas la mateixa funció (locativa) que el relatiu on (i per tant no hi hauria duplicació); però encara avui molts professionals es resisteixen a acceptar el pronom, influits per aquella vella temença de "pleonasme".

Un altre exemple comparable seria el de (6d): el quantificador bastant té avui quatre terminacions ("Tinc bastant mal de cap, bastanta feina, bastants dies de festa, bastantes raons per creure-ho"), igual que d'altres adjectius com blau; però antigament aquesta paraula funcionava de manera diferent i no tenia terminació per al gènere ("No té lo món coses a mi bastants", Ausiàs March). D’altra banda, no tots els parlars catalans l'han adoptada: els valencians no la coneixen i utilitzen prou (Té prou diners). La sensació (injustificada) de solecisme que un dia es va instal-lar en aquesta paraula ha provocat que fins avui molts professionals es resisteixin a acceptar bastanta, bastantes, i l'autoritat lingüística no ha despenalitzat aquestes formes fins fa quatre dies, i encara amb molta recança. Però resulta que no hi ha cap parlant que pugui prescindir d'aquestes formes: ningú no podria dir mai, de cap manera, en una conferència, en un sobretaula, en una pel·lícula, Té bastants preocupacions.

Finalment, és important de dir que l'home del carrer no sap o no pot distingir entre els codis sancionats i la resta de material pedagògic i de suport del mercat (llibres d'estil, manuals escolars, diccionaris de barbarismes, etc.), material que, com he dit, gairebé sempre es manté en posicions cautelars, és a dir "ortodoxes" o clàssiques.

\subsection{Actitud de la Gcc}

En principi, la Gcc no té com a missió ni establir ni reforçar ni recordar ni reproduir la norma, i de fet la immensa majoria de les seves pàgines són alienes als problemes normatius. Tanmateix, quan es presenta un aspecte que té algun dictamen normatiu, en general el redactor fa esment d'aquest aspecte i si vol el comenta assentint-hi o dissentint-ne. La Gcc té un altre objectiu: descriure de manera àmplia la realitat de la llengua, perquè en puguem tenir una coneixença que vagi més enllà de les necessitats peremptòries. Fins fa molt poc, i sempre per les mateixes raons socials i polítiques ja dites (la llengua catalana no era una llengua "alta", no era llengua d'escola, de televi- 
sió, de cine, de conferències, de llibres de ciència), tot el que hi havia eren manuals d'urgència que només s'ocupaven de quatre detalls considerats prioritaris (en general, usos divergents respecte de la llengua imposada).

Vegem algun cas en què la Gcc comenta la normativa. En la qüestió de la supressió del guionet amb el prefix ex-(6j), a la pàgina 786 es diu: "En la revisió que l'IEC [Institut d'Estudis Catalans] fa actualment de la gramàtica normativa sembla que el prefix $e x$-admetrà guionet en casos de mots no consolidats (ex-governamental, ex-marit), i aquest és l'ús que s'ha adoptat en aquesta Gramàtica". En aquest punt, evidentment hi va prendre cartes la mateixa direcció de la GCc (vg. altres pàgines afectades: 796-797, 817, 1290).

Sobre la concordança negativa o negació doble (Ningú (no) bo ha vist) (6i), l'autora del capítol (M. Teresa Espinal) diu això: "Les gramàtiques tradicionals insisteixen a remarcar que no convé suprimir l'adverbi no quan els mots negatius apareixen en posició preverbal [...]. No obstant [...], la tendència en el llenguatge parlat actual i en el llenguatge dels mitjans de comunicació és a prescindir del marcador no" (p. 2767; vg. també p. 2775).

La pronominalització dels atributs definits (6h) és una qüestió que s'arrossega des de fa molts anys. Fabra va apostar per distingir aquest cas dels altres i per tant feia pronominalitzar amb els pronoms definits el, la, els, les. Diversos gramàtics han posat seriosament en qüestió aquest fenomen. El gallec sembla que és una de les llengües en què el fenomen es manifesta clarament, encara que hi és possible la pronominalització definida i la neutra (a part alguna altra solució, com ¿Dis que non é túa nai? Ser non será ela, pero parecer parece), com m'informa Rosario Álvarez (vg. (6h)). L'autora d'aquesta part de la Gcc (Júlia Todolí) aposta decididament per l'eliminació del pronom definit: "Coromines va fer un pas endavant [...]. Algú hauria de fer el següent pas i eliminar definitivament el pronom definit de la funció d'atribut" (p. 1411).

Pel que fa al fenomen dit de "canvi i caiguda de preposicions", el català normatiu prescriu la desaparició de preposicions febles davant la conjunció que (No m'he recordat [de] que havia de venir el teu germà) i el canvi de en i $a m b$ en $a$ o de davant l'infinitiu (Confía en el seu germà; però Confia d'acabar-ho avui mateix). L'autor del capítol de les preposicions (Pelegrí Sancho) fa notar que ens falta un estudi de la realitat de la llengua parlada, però assegura que "Segurament avui dia els usos no normatius estan molt més estesos que en el temps en què Fabra elaborà la normativa", etc. (p. 1720). 
La direcció de la Gcc, d'altra banda, va prendre diverses precaucions en aquest terreny.

a) En primer lloc, va definir clarament quins cren els codis normatius sancionats i va procurar que cap autor no els confongués amb la resta d'obres de consulta. En el llibre d'estil de la Gcc s'establia que s'utilitzés el concepte normatiu únicament per referir-se a les obres normatives oficialment sancionades, i que en els altres casos es recorregués a perífrasis com ara les següents: "En general, \{les gramàtiques / els gramàtics\} consideren/diuen...", "Hi ha una certa tradició...", "Certs manuals defensen...", "L’opció estilísticament recomanada per certs gramàtics...".

b) En segon lloc, en el mateix llibre d'estil la direcció va referir-se a uns quants detalls dels que hem esmentat més amunt i a d'altres de no esmentats i va dir com s'havien de tractar aquests detalls en la llengua de redacció. Per exemple, van quedar com a fets lliures (optatius per als redactors) els següents: la concordança del verb haverhi (6c) (efectivament, en algun capítol hi ha concordança sistemàtica), l'ùs de les preposicions per i per $a$ amb infinitiu (6b); l'ús de en o al amb l'infinitiu temporal (6e); la concordança negativa (6i); la presència de de en construccions com davant, darrere, damunt (de) la taula; l'ús del "subjecte" a la vora de la locució no obstant (per tant, es podia escriure no obstant això, però també simplement no obstant); la introducció amb de de certs infinitius complements o subjectes (Convindria (d')anar-bi).

En altres casos la direcció va prescriure un sol ús. Per exemple, en els següents: les terminacions nominals de plural en -scs, -sts, -xts (normals en certes parles no majoritàries) normalment s'havien d'evitar (per tant, calia escriure boscos, contrastos, textos i no boscs, contrasts, texts); l'infinitiu ésser s'havia de substituir pel modern i general ser; els signes d'interrogació i exclamació (6a) s'havien d'usar sistemàticament davant i darrere dels elements afectats (sense cap excepció); els adverbis en -ment coordinats havien d'acabar tots en aquesta terminació (dicticament o anafôricament, no pas dicticament o anafôrica, com era possible en català antic).

c) La direcció de la Gcc va vigilar també que el corrector d'estil de l'obra no imposés certs usos als autors que no els acceptaven. El cas més espectacular d'això el va constituir l'ús de les preposicions locatives $a$ i en (6g). El corrector aplicava en aquest punt una teoria prò- 
pia que xocava a més d'un autor. Per exemple, el corrector canviava en $e n$ la $a$ de casos com aquests dos: "Com hem vist $a$ (23b), l'infinitiu..."; "aquells detalls (i molts altres) es troben vacillants en tots dos grups, però especialment al primer"; i diversos autors van reclamar que s'hi restituís la $a$, cosa que va fer la direcció. Cal tenir en compte que una obra com aquesta és producte de professionals de la llengua catalana, i per tant calia prendre moltes precaucions a no imposar usos que no fossin absolutament segurs o bé usos que (com el que acabem de citar) són precisament discutits. 